\title{
К вопросу о национальном профиле телевидения \\ в эпоху глобализации: опыт ведущих французских телеканалов
}

\author{
Горобий А.В. \\ Тверской государственный университет, \\ Россия, 170100, г. Тверь, ул. Желябова, 33 \\ E-mail: alexogor@mail.ru
}

\begin{abstract}
Аннотация. Статья посвящена жанровому анализу телепрограмм трех ведущих французских телеканалов (TF1, France 2 и France 3) с точки зрения соотношения в эфире этих телеканалов оригинальных и зарубежных (заимствованных) элементов. Анализ включает в себя рассмотрение как собственно телевизионных жанров, так и более частных категорий, а именно особенностей работы журналистов и операторов. Руководствуясь семиотическим подходом, автор интерпретирует эти две стороны телевизионного творчества в их взаимосвязи и стремится выявить их смысловое единство, обусловливающее профиль как отдельных передач, так и телеканалов в целом. Выводы автора говорят о корреляции между организационно-правовым статусом телеканалов и преобладанием в их эфире национальных или глобальных черт.
\end{abstract}

Ключевые слова: телевидение, Франция, глобализация, традиции, жанры.

Для цитирования: Горобий А.В. 2020. К вопросу о национальном профиле телевидения в эпоху глобализации: опыт ведущих французских телеканалов. Вопросы журналистики, педагогики, языкознания, 39 (4): 524-532. DOI 10.18413/2712-7451-2020-39-4-524-532

\section{To the Issue of the National Profile of the Television in Times of Globalization: the Case of the Main French Channels}

\author{
Alexey V. Gorobiy \\ Tver State University \\ 33 Zhelyabov St, Tver, 170100, Russia \\ E-mail: alexogor@mail.ru
}

\begin{abstract}
The article focuses on the analysis of genres of the programme at the main French TV channels (TF1, France 2 and France 3) with regard to the proportion of original and alien (imported) elements. The analysis covers the TV genres as well as more particular categories, namely the specifics of journalists' and cameramen's work. Following the semiotic approach, the author considers these two sides of the television production in their interrelation and seeks to reveal their semantic unity, which determines the profile of individual broadcasts and the TV channels in their entirety. The social mission of the television comprising both entertaining the audience (while perpetuating the cultural heritage) and addressing the urgent public issues (politics, religion, crimes etc.) is also dealt with in the paper. The author's conclusions demonstrate a certain correlation between the legal and institutional framework of TV channels on one side and the prevalence of national or global elements in their broadcasts on the other side. These conclusions are meant to enrich the Russian studies of journalism abroad as well as to help today's Russian TV channels develop their unique profile in times of globalization and virtualization.
\end{abstract}

Keywords: television, France, globalization, traditions, genres. 
For citation: Gorobiy A.V. 2020. To the Issue of the National Profile of the Television in Times of Globalization: the Case of the Main French Channels. Issues in Journalism, Education, Linguistics, 39 (4): 524-532 (in Russian). DOI 10.18413/2712-7451-2020-39-4-524-532

\section{Введение}

Телевидение - международное явление, развивающееся во многом параллельно с глобализацией и формированием единого мирового информационного пространства. В наши дни интернациональный характер телевещания только усиливается его виртуализацией, переводом в режим интернет-трансляций. Однако те же условия рынка, которые направляют телевидение по пути интернационализации, требуют от телеканалов каждой страны сохранять свой оригинальный профиль для того, чтобы быть интересными аудитории и поддерживать свои позиции на медиарынке. Франция известна бережным, протекционистским отношением к своему языку и культуре, поэтому и работа ее телеканалов интересна, среди прочего, как опыт развития своих жанровых особенностей в глобальной информационной среде.

В российской науке есть ограниченный круг работ, касающихся телевидения за рубежом, - это работы Л.В. Шарончиковой [2011], Н.А. Голядкина [2011], Р.А. Борецкого [2011], И.И. Гачечиладзе [2006], А.В. Васильевой [2013], однако в них акцент делается в основном на организационно-правовой и технико-экономической стороне развития телевещания в других странах. Жанровая специфика, особенности творчества тележурналистов и телеоператоров освещаются в названных трудах недостаточно полно. В то же время есть большой пласт теоретических, отчасти философских исследований [Бурдье, 2002; Маклюэн, 2003; Луман, 2005; Вартанова, 2019], которые важны для понимания общих тенденций развития мировых средств массовой информации (СМИ) и, в частности, телевидения, однако они опять же не содержат конкретного анализа жанровых форм, особенностей и путей эволюции телепередач в отдельных странах. В связи с этим цель данной статьи - проанализировать особенности французского телевидения в эпоху глобализации, внеся тем самым вклад в изучение проблем зарубежного телевидения.

\section{Объекты и методы исследования}

В настоящее время во Франции завершен переход к цифровому телевидению: есть 8 мультиплексов, которые включают в себя 32 обязательных канала - 25 бесплатных и 7 платных, а также несколько десятков необязательных каналов. Среди них - канал французского парламента, специализированные новостные, спортивные каналы, каналы для регионов и заморских территорий (Мартиника, Гваделупа, Гвиана, Реюньон, Полинезия) [PAF: le paysage audiovisuel français]. Наивысшие рейтинги имеют каналы TF1 (19,5 \% аудитории), France $2(13,9 \%)$ и France $3(9,9 \%)$ [Communiqué de presse]. Передачи этих трех каналов составляют объект исследования в рамках данной статьи. Предметом исследования являются жанровые особенности телепередач, а именно присутствие или преобладание в них национальных или глобальных культурных элементов.

Исследование было проведено на основе семиотической методологии: данная методология уже много лет применяется как для анализа текстов [Иванов, 2004], так и для изучения кино и других видов визуального творчества [Тынянов, 1977; Барт, 2011]. Предложенный московско-тартуской школой целостный подход к изучению культуры [Лотман, 2010] подразумевает возможность распространения сферы применения семиотической методологии и на телевизионную продукцию (как часть культуры), являющуюся, как известно, синтезом изображения и слова [Светана, 1976, с. 65], визуального и вербального творчества. 


\section{Результаты исследования}

TF1 - исторически первый французский телеканал, созданный в 1935 г., когда началось регулярное вещание в формате электронного телевидения на коротких волнах с Эйфелевой башни. До 1987 г. он был государственным и представлял собой оплот системы государственного контроля над телевидением, однако в 1987 г. был приватизирован в русле политики либерализации информационной сферы [Голядкин, 2011].

Как на заре телевещания, так и в наши дни «костяк» телепрограммы TF1 составляют информационные передачи. Старейшей из них является «Телегазета» (Journal Télévisé), выходящая в эфире TF1 (тогда RTF Télévision) с 1949 г. В настоящее время «Телегазета» (точное современное название - «Газета в 20:00» (Le Journal de 20 heures) остается символом французского телевидения и каждый вечер собирает у телеэкранов более 6 млн телезрителей [Top 30 des JT les plus regardés]. Однако на первом канале сейчас есть и другие информационные передачи более широкого профиля, чем чисто новостная «Телегазета». В частности, информационный журнал «С семи до восьми» специализируется на более крупных журналистских жанрах, чем работающая в режиме коротких актуальных заметок «Телегазета»: «С семи до восьми» состоит, как правило, из 4-5 больших репортажей. У данного журнала есть разновидность «С семи до восьми. Жизнь», имеющая социальную направленность и представляющая телезрителям репортажи о жизни французов и других народов. Формат этих информационных передач, включающий в себя «заставку», «шпигель», «подводки» ведущего и собственно репортажи (либо сюжеты, зарисовки), является стандартным для большинства стран мира, однако исследователи отмечают его американские корни и соответственно рассматривают как проявление «американизации» французского телевидения в такой «политически важной» сфере, как новости [Bourdon, 2011, p. 222].

К информационному и информационно-аналитическому жанру примыкают документальные передачи, многие из которых прославили в свое время телеканал TF1. Среди них - циклы «Жизнь животных» Фредерика Россифа и Клода Дорже (1952-1966 гг.), «Лекции для всех» (первая литературная передача французского телевидения, 19531968 гг.), «Глазами зрителя» (La Séquence du spectateur, передача о кино, ныне возрожденная под названием «Новыми глазами зрителя» на канале Télé Mélody). Эти передачи наряду с журналистской работой знамениты своим визуальным оформлением, а именно художественно проработанными и имеющими хорошее музыкальное сопровождение заставками. Тем самым эти передачи заложили основу той стратегии смыслового единства (синтеза) словесной и визуальной семантики, которая в наши дни широко распространена в журналистской работе и которая коренится в модернистской (постмодернистской) установке на максимальную эффективность коммуникации [Bourdon, 2011, p. 227].

Для художественной продукции канала TF1 характерно внимание к социальным сторонам жизни: телероман (мыльная опера) «Завтра наш день», демонстрируемый с 2017 г., повествует о жителях маленького средиземноморского городка и их проблемах. В данном сериале, выходящем в прайм-тайм и потому имеющем большую аудиторию, регулярно поднимаются острые социальные и криминальные темы [Demain nous appartient]. В эфире TF1 присутствует значительная доля импортной продукции: в разное время на этом канале демонстрировались американские сериалы «Хороший доктор», «S.W.A.T.» (Special Weapons And Tactics), «Манифест».

Еще более интернациональный профиль наблюдается в развлекательном секторе телепрограммы TF1. Прежде всего следует сказать о французских версиях большого числа зарубежных шоу и телеигр: это и нидерландский вокальный конкурс «Голос», и южнокорейское вокальное соревнование «Певец в маске», и британское шоу «Танцы со звездами», и немецкое спортивное шоу «Большой прыжок, бег по батутам», и американские игры «Колесо фортуны» (1987-2012 гг.), «Большая сделка» (1998-2004 гг.), «Кто хочет выиграть миллионы», и аргентинская игра «Двенадцать ударов в полдень». Кроме того, на 
TF1 в течение двух последних десятилетий транслировалось немало реалити-шоу, которые без исключения являлись адаптациями зарубежных аналогов - нидерландского шоу «Большой брат» (Loft Story во Франции), шведского «Последний герой» (Koh-Lanta во Франции), британских «Шеф-повар» и «Я знаменитость, заберите меня отсюда». Все эти шоу адаптируются главным образом в языковом и географическом плане (места съемок), но не с точки зрения культуры и менталитета. В любой стране они остаются форматизированной продукцией, производящейся по лицензии.

Поэтому с точки зрения национального профиля французского телевидения больший интерес представляют оригинальные развлекательные передачи, которых на канале TF1 по-прежнему немало и которые ранее представляли собой один из оплотов культурного протекционизма в телевизионной сфере [Bourdon, 2011, p. 220]. Варьете - исконно французский формат развлечения публики, в котором (в отличие, скажем, от немецкого кабаре) акцент делается не на социально-критической, а на увеселительной функции. Одним из первых телевизионных варьете на французском телевидении была передача «36 свечей» (1952-1958 гг.) [Emissions TV. 36 chandelles]. По ее выпускам мы можем заметить, что при сохранении оригинального формата эта передача была открыта для элементов иных культур: ведущие часто обращались к зрителям на разных языках, в эфире звучали иностранные песни (например, английские шлягеры в исполнении Мирей Матьё).

Достоинством французского телевидения, наряду с творчеством журналистов, является мастерство операторов. Особенно это заметно по таким необычным авторским передачам 1960-х гг., как «Зеленый виноград» Жана-Кристофа Аверти, отличавшимся экспериментальным, новаторским подходом к съемкам [La télé-génie de Jean-Christophe Averty]. В наши дни мода на причудливые ракурсы уже в основном ушла в прошлое, уступив место разнообразию применяемых технических средств и акценту на визуальной привлекательности кадра. Большой простор для творчества операторов открывают такие познавательно-развлекательные передачи, как «Ушуайя, экстремальный журнал» (Ushuaïa, le magazine de l'extrême). Данный журнал (в эфире в 1987-2014 гг.) показывал телезрителю природу и жизнь народов в разных уголках планеты, а также уделял немало внимания экстремальным видам спорта [Raveleau]. Есть на канале TF1 и специализированный журнал «Автомото» - старейший французский спортивный тележурнал, выходящий с 1975 г.

France2 был организован в 1964 г. как телеканал, имеющий статус общественного и находящийся под управлением общественного совета, что налагало на этот канал обязанность выполнять традиционную миссию общественного телевидения по «информированию - просвещению - развлечению» (informer, cultiver, distraire) [Bourdon, 2011, p. 214] своей аудитории. По сравнению с каналом TF1 необходимо отметить бо́льшую долю информационных передач в программе France 2 и их большее разнообразие. Наряду с собственно выпусками новостей данный канал предлагает зрителям тележурнал репортажей «Специальный вестник» и два тележурнала в русле расследовательской журналистики «Дополнительное расследование» и «Финансовое расследование» (Cash Investigation - англоязычное название). Для двух последних журналов характерна все чаще встречающаяся на телевидении смесь документальных и художественных элементов [E-dossiers de l'audiovisuel, p. 3]: на фактическую, хроникальную основу накладываются постановочные элементы, призванные визуализировать, художественно подчеркнуть важнейшие эпизоды расследуемых дел. Еще более эстетически проработанным является документальный цикл «Введите обвиняемого» (c 2020 г. на канале RMC Story), рассказывающий о самых громких преступлениях в истории Франции. Для него характерны художественные съемки со спецэффектами, которые дополняют и обогащают журналистский текст, обеспечивая возможность порождения новых дискурсивных смыслов и эмоциональных оценок в сознании аудитории.

Разнообразие журналистских жанров проявляется и в наличии в программе France 2 ток-шоу «Мы не спим», выходящего по субботам в 23:00 (жанр ток-шоу был за- 
имствован из американского телевидения в 1960-х гг. [Bourdon, 2011, p. 224]). Название имеет двойной смысл: позднее время и обязанность журналистов «никогда не дремать, всегда бодрствовать духом» [On n'est pas couché]. Данное ток-шоу относится к категории инфотейнмент: включает в себя серьезные и развлекательные темы, а в число гостей передачи входят общественные деятели, писатели, журналисты, драматурги. Ведущие стараются поддерживать непринужденную атмосферу живого общения, избегая как излишней конфронтационности, так и чрезмерной серьезности, что соответствует последним тенденциям развития жанра ток-шоу в Европе [Forsgren, Sullet-Nylander, 2010, p. 76-101].

Сближение информационных передач с развлекательными - это лишь одна из тенденций программной политики телеканала France 2. Другой тенденцией является пересечение новостного и документально-познавательного жанров, как это имело место в международном геополитическом тележурнале «Взгляд на планету», выходившем в эфир в 2002-2017 гг. под девизом «смотри - задавай вопросы - понимай» [Fiche pédagogique. Un œil sur la planète]. Есть на France 2 и чисто познавательный, научно-популярный цикл «Экстраординарные способности человеческого тела», в рамках которого операторы вносят значительный вклад в то, чтобы научный материал вызывал интерес и был доступен для понимания телезрителями (за счет широкого использования макропланов, многокамерной съемки и т.д.).

В развлекательном секторе телепрограмм канал France 2 обнаруживает приверженность оригинальным французским компонентам: следует отметить эстрадное шоу «Лучшее кабаре в мире» (1998-2019 гг.) и, конечно же, знаменитую телеигру «Форт Боярд», проводящуюся с 1990 г. Съемки, как известно, проходят в форте на атлантическом побережье Франции, где команды должны пройти физические и интеллектуальные испытания для того, чтобы завоевать сокровище. Игра имеет зарубежные версии, которые снимаются в этом же форте [Les versions étrangères de Fort Boyard].

Одной из визитных карточек французского телевидения считается игра «Встреча городов» (Intervilles), которая выходит в эфир с 1962 г. (с перерывами) и в 2021 г. будет возобновлена на канале France 2. Первоначально формат игры предполагал встречу команд из двух городов Франции, которым предлагались задания на физическую выносливость и интеллект (съемки под открытым небом или в крытой арене за пределами студии). В настоящее время формат расширился, и игры зачастую проводятся в международном масштабе с участием команд из разных стран. «Встреча городов» послужила основой для большого количества адаптаций за рубежом [L'émission culte Intervilles...]. Данная игра - пример того, как оригинальное французское содержание оказывается базой для интернационализации телевизионной продукции, не мешает открытости и помогает культурному обмену.

Перечень художественных фильмов и сериалов, демонстрировавшихся в разное время на канале France 2, свидетельствует о той же открытости для зарубежной продукции, которую мы отмечали применительно к первому французскому телеканалу: здесь есть и французская («Маленькие убийства Агаты Кристи»), и немецкая («Инспектор Деррик»), и американская («ФБР: пропавшие без вести», «Нераскрытые преступления», «Замок»), и австро-итальянская («Рекс, полицейский пес»), и британская («Бродчёрч») продукция. Активное использование импортной продукции связано с борьбой общественного французского телевидения за рейтинги, обострившейся после реформы Николя Саркози 2009 г. (запрет рекламы с 20:00 до 6:00) [Васильева, 2013, с. 14-15].

Важный аспект программной политики France 2 - присутствие в ней религиозной передачи «День Господа» (Le Jour du Seigneur), выходящей в эфир в воскресенье по утрам с 1949 г. Франция - преимущественно католическая страна, поэтому, в отличие от Германии (страны, отчасти католической, отчасти протестантской), на французском телевидении нет мультиконфессиональности. В рамках телепередачи «День Господа» транслируются исключительно католические богослужения. 
France 3 - это также общественный телеканал, созданный в 1972 г. и вместе с France 2 входящий в состав телерадиокомпании France Télévisions. Главная особенность канала France 3 была заложена при его учреждении: это телеканал, призванный освещать жизнь регионов - как во французской метрополии, так и на ее заморских территориях (Мартиника, Гваделупа, Гвиана, Реюньон, Полинезия) [Шарончикова, 2011, с. 152-153]. В наши дни региональный профиль данного телеканала стал весьма широким и разноплановым. На канале в 19:00 выходит «Региональная телегазета», после нее «Региональный прогноз погоды» и в 19:30 - «Национальная телегазета», т.е. в телепрограмме происходит совмещение общенационального и регионального информационного поля.

Передачи часто записываются в провинциальных французских городах, в сельской местности. Это позволяет не только привносить региональный антураж в эфир одного из центральных телеканалов, но и увязывать столичный и провинциальный аспекты истории, культуры и общественной жизни Франции. В частности, документальные циклы «Секреты истории» и «Один день, одна судьба», рассказывающие о выдающихся личностях и важнейших событиях французской и всемирной истории, неизменно показывают региональные истоки этих событий - например, места рождения Шарля де Голля, Жака Ширака или места народных движений во время Великой французской революции.

Исключительное место на телеканале France 3 занимают познавательные передачи: их можно назвать и научно-популярными, однако главный акцент в них делается на личностно-субъективном взгляде, открытии для себя разных, порой самых экзотических мест на Земле (они так и называются - «журналы открытий», magazines de découvertes). Таковы тележурналы «Таласса», повествующий о море с точки зрения экологии, спорта, промыслов и т.д., «Не нужно мечтать», посвященный путешествиям авторов - журналистов Филиппа Гуглера и Каролины де Сальво - по разным странам и континентам, и «Счастливчики» (Échappées belles), имеющий более страноведческий, культурологический характер. Документальный цикл «Корни и крылья», напротив, сосредоточен на показе внутренних территорий Франции, исторических памятников, природных заповедников и иных достояний культуры, косвенно следуя тем самым установке первого министра культуры Пятой республики Андре Мальро на создание «музеев без стен» [Гачечиладзе, 2006, с. 5]. Миссия этого цикла, сформулированная его ведущей Кароль Гэсслер, звучит так: «Показывать прошлое для прояснения настоящего и прокладывания тропинки в будущее, а также освещать деятельность людей на Земле» [Montpellier à l'écran...].

В области развлечений телеканал France 3 также не изменяет своему региональному профилю. Наряду со старейшей французской телеигрой «Цифры и буквы», выходящей с 1965 г. (вначале на France 2), в телепрограмме France 3 следует выделить игру «Карта сокровищ» (La Carte aux trésors): в ходе поиска сокровищ участники передачи изучают историю и культуру городов и сел Франции и ее заморских территорий. При записи этой игры, как и при создании названных выше познавательных тележурналов, чрезвычайно большую роль играют съемки с воздуха, с вертолетов и квадрокоптеров [Langlade, 2018], помогающие телезрителю увидеть всю красоту ландшафтов, природы, архитектурных сооружений.

Канал придает существенное значение трансляциям концертов (особенно классической музыки) и спортивных соревнований (Олимпийских игр, теннисного турнира «Ролан Гаррос», велогонки «Тур де Франс»). Есть на France 3 и свой спортивный тележурнал «Стадион 2» (Stade 2), появившийся еще в 1975 г.

\section{Заключение}

Подводя итоги, следует обратить внимание на то, что юридический и экономический статус того или иного телеканала влияют на то, как в его программной стратегии сочетаются тенденции к интернационализации и, наоборот, к сохранению культурных традиций. Телеканал TF1 был приватизирован в 1987 г. и после этого, ориентируясь на 
настроения «средней Франции», сделал своим профилем развлекательные (отчасти информационно-развлекательные) передачи. В данном секторе, несмотря на успешное сохранение многих исконно французских культурных форм (варьете), все же наблюдается преобладание международных лицензионных форматов, лишенных национальной специфики. После приватизации TF1 France 2 оказался, в сущности, основным общественным телеканалом и сделал ставку на более интеллектуальные передачи, не боясь потерять часть аудитории и следуя традициям общественного вещания Би-Би-Си. В этом русле в настоящее время в телепрограмме France 2 отмечается большое разнообразие информационных жанров, многие из которых требуют художественного оформления (телевизионные расследования). Акцент на визуальной привлекательности возрастает в познавательных тележурналах France 2 и становится едва ли не доминирующим в эфире France 3, однако на этом канале он выполняет, наряду с развлекательной, и другую важную функцию - популяризации своей страны, ее регионов, их природных богатств и культурного достояния. В целом можно констатировать, что эстетика кадра помогает обоим общественным каналам - France 2 и France 3 - сочетать установки на интеллектуальность и на рыночную конкурентоспособность своей экранной продукции, обеспечивая при этом «культурное разнообразие» и «регионализацию» телеэфира. Тем самым даже в области развлечений им удается поддерживать популярность оригинальных французских передач - «Встреча городов», «Форт Боярд», «Карта сокровищ» и др.

\section{Список источников}

1. Demain nous appartient. Informations. URL: https://www.tf1.fr/tf1/demain-nous-appartient (accessed: 23 July 2020).

2. Communiqué de presse. Médiamat Mensuel. Audience en jour de vision. Juin 2020 - du 1er au 28 Juin 2020. Levallois, le 29 juin 2020. URL: https://www.mediametrie.fr/sites/default/files/202007/2020\%2006\%2029\%20CP\%20Mediamat\%20Mensuel\%20Juin\%202020.pdf (accessed: 19 July 2020).

3. E-dossiers de l'audiovisuel: Le documentaire, un genre multiforme. Novembre 2013, 3. URL: https://www.lerecit.fr/wp-content/uploads/2018/03/le_documentaire-UN-GENRE-MULTIFORME. pdf (accessed 22 July 2020).

4. Emissions TV. 36 chandelles. URL: https://www.toutelatele.com/36-chandelles-38598 (accessed: 24 July 2020).

5. Fiche pédagogique. Un ail sur la planète. URL: http://www.tv5monde.com /TV5Site/upload_image/app_fp/fiche_complete/oeil_planete.pdf (accessed: 24 July 2020).

6. Langlade C. 2018. «La Carte aux Trésors» revient sur France 3. In: Le Monde, 23 avril 2018. URL: https://www.lemonde.fr/televisions-radio/article/2018/04/23/la-carte-aux-tresors-revient-sur-france3_5289390_1655027.html (accessed: 24 July 2020).

7. télé-génie de Jean-Christophe Averty. URL: https://www.francetvpro.fr/france3/programmes/634037 (accessed: 24 July 2020).

8. La L'émission culte Intervilles sera de retour sur France 2 en 2020. URL: https://www.sudouest.fr/2019/12/19/1-emission-culte-intervilles-sera-de-retour-sur-france-2-en-20206976376-4608.php (accessed: 23 July 2020).

9. Les versions étrangères de Fort Boyard. URL: https://www.fan-fortboyard.f r/pages/emission/versions-etrangeres-de-fort-boyard.html (accessed 24 July 2020).

10. Montpellier à l'écran dans «Des racines et des ailes» sur France 3 - Mercredi 11 septembre dès 20h50. URL: http://www.montpellier-agglo.fr/actualite/montpellier-lecran-dans-des-racines-et-desailes-sur-france-3-mercredi-11-septembre-des (accessed: 24 July 2020).

11. «On n'est pas couché»: Laurent Ruquier révèle le sens caché du nom de l'émission. URL: https://soirmag.lesoir.be/311540/article/2020-07-06/nest-pas-couche-laurent-ruquier-revele-le-senscache-du-nom-de-lemission (accessed: 24 July 2020).

12. PAF: le paysage audiovisuel français. Les chaînes de la TNT. In: Le Conseil supérieur de l'audiovisuel (CSA). URL: https://www.csa.fr/Informer/PAF-le-paysage-audiovisuel-francais/Leschaines-de-la-TNT (accessed: 23 July 2020). 
13. Raveleau A. Ushuaïa Nature en attente des 10 millions de fidèles sur TF1. URL: https://www.toutelatele.com/ushuaia-nature-en-attente-des-10-millions-de-fideles-sur-tf1-3925 (accessed: 24 July 2020).

14. Top 30 des JT les plus regardés: TF1 fait main basse sur l'Europe. URL: https://www.toutelatele.com/top-30-des-jt-les-plus-regardes-tf1-fait-main-basse-sur-1-europe-59872 (accessed: 23 July 2020).

\section{Список литературы}

1. Барт Р. 2011. Camera lucida. Комментарий к фотографии. Пер. с фр. М. Рыклина. М., Ад Маргинем Пресс, 272 с. (Barthes R. 1980. La Chambre Claire. Éd. Gallimard. Paris, 192 p.)

2. Борецкий Р.А. 2011. Беседы об истории телевидения. Лекции, прочитанные на факультете журналистики МГУ в феврале - мае 2010 г. М., Издательство Икар, 178 с.

3. Бурдьё П. 2002. О телевидении и журналистике. Пер. с фр. Т. Анисимовой, Ю. Марковой. Под ред. Н. Шматко. М., Прагматика культуры, Институт экспериментальной социологии, 160 с. (Bourdieu P. 1996. Sur la télévision. Suivi de l'emprise du journalisme. Paris, Liber-Raisons, 96 p.)

4. Вартанова Е.Л. 2019. Теория медиа: отечественный дискурс. М., Факультет журналистики МГУ им. М.В. Ломоносова, Изд-во Московского ун-та, 221 с.

5. Васильева А.В. 2013. Общественное телевидение Франции в эпоху внедрения цифровых технологий (2008-2013 гг.). Автореферат дис. ... канд. филол. наук. М., 21 с.

6. Гачечиладзе И.И. 2006. Телевидение Франции в контексте национальной культурной политики. Автореферат дис. ... канд. филол. наук. М., 23 с.

7. Голядкин Н.А. 2011. История отечественного и зарубежного телевидения. М., Аспект Пресс, 189 c.

8. Иванов В.В. 2004. Лингвистика третьего тысячелетия: вопросы к будущему. М., Языки славянских культур, 208 с.

9. Лотман Ю.М. 2010. Семиосфера. СПб., Искусство-СПБ, 703 с.

10.Луман Н. 2005. Реальность массмедиа. Пер. с нем. А. Ю. Антоновского. Под ред. О.В. Кильдюшова. М., Праксис, 256 с. (Luhmann N. 2004. Die Realitat der Massenmedien. Wiesbaden, VS Verlag für Sozialwissenschaften, 219 p.)

11.Маклюэн М. 2003. Понимание Медиа: Внешние расширения человека. Пер. с англ. В. Николаева. М., Жуковский, КАНОН-пресс-Ц, Кучково поле, 464 с. (McLuhan М. 1964. Understanding Media: The Extensions of Man. New York, McGraw-Hill, 318 p.)

12. Светана С.В. 1976. Телевизионная речь. Функции и структура. Под ред. Я.Н.Засурского. М., Изд-во Моск. ун-та, 151 с.

13.Тынянов Ю.Н. 1977. Об основах кино. В кн.: Тынянов Ю.Н. Поэтика. История Литературы. Кино. Под ред. В Каверина. М., Наука: 326-348. та, $222 \mathrm{c}$.

14.Шарончикова Л.В. 2011. Радиовещание и телевидение Франции. М., Изд-во Моск. ун-

15.Bourdon J. 2001. Genres télévisuels et emprunts culturels. L'américanisation invisible des télévisions européennes. Réseaux, 107 (3): 209-236.

16.Forsgren M., Sullet-Nylander F. 2010. Genre médiatique, activités linguistiques et degré d'interactivité. Le cas du talk-show. In: Communication, 27(2): 76-101. URL: https://journals.openedition.org/communication/3080\#tocto1n5 (accessed: 22 July 2020).

\section{References}

1. Bart R. 2011. Camera lucida. Kommentarij k fotografii [Camera lucida. Commentary on the photo]. M., Publ. Ad Marginem Press, 272 p. (Barthes R. 1980. La Chambre Claire. Éd. Gallimard. Paris, 192 p.)

2. Boreckij R.A. 2011. Besedy ob istorii televidenija. Lekcii, prochitannye na fakul'tete zhurnalistiki MGU v fevrale - mae $2010 \mathrm{~g}$. [Conversations about the history of television. Lectures given at the Faculty of Journalism of Moscow State University in February - May 2010]. M., Publ. Ikar, 178 p. 
3. Burd'jo P. 2002. O televidenii i zhurnalistike [On television and journalism]. Ed. N. Shmatko. M., Publ. Pragmatika kul'tury, Institut jeksperimental'noj sociologii, 160 p. (Bourdieu P. 1996. Sur la télévision. Suivi de l'emprise du journalisme. Paris, Liber-Raisons, 96 p.)

4. Vartanova E.L. 2019. Teorija media: otechestvennyj diskurs [Media theory: domestic discourse]. M., Publ. Fakul'tet zhurnalistiki MGU im. M.V. Lomonosova, Publ. Moskovskogo un-ta, 221 p.

5. Vasil'eva A.V. 2013. Obshhestvennoe televidenie Francii v jepohu vnedrenija cifrovyh tehnologij (2008-2013 gg.). Avtoreferat dis. ... kand. filol. nauk. [French Public Television in the Digital Age (2008-2013)]. Abstract dis. ... cand. philol. sciences. M., 21 p.

6. Gachechiladze I.I. 2006. Televidenie Francii v kontekste nacional'noj kul'turnoj politiki. [Television of France in the context of national cultural policy]. Abstract dis. ... cand. philol. sciences. M., 23 p.

7. Goljadkin N.A. 2011. Istorija otechestvennogo i zarubezhnogo televidenija [History of domestic and foreign television]. M., Publ. Aspekt Press, 189 p.

8. Ivanov V.V. 2004. Lingvistika tret'ego tysjacheletija: voprosy $\mathrm{k}$ budushhemu [Linguistics of the Third Millennium: Questions for the Future]. M., Publ. Jazyki slavjanskih kul'tur, 208 p.

9. Lotman Ju.M. 2010. Semiosfera [Semiosphere]. SPb., Publ. Iskusstvo-SPB, 703 p.

10. Luman N. 2005. Real'nost' massmedia [Reality of the mass media]. Ed. O.V. Kil'djushov. M., Publ. Praksis, 256 p. (Luhmann N. 2004. Die Realitat der Massenmedien. Wiesbaden, VS Verlag für Sozialwissenschaften, 219 p.)

11. Makljujen M. 2003. Ponimanie Media: Vneshnie rasshirenija cheloveka [Understanding Media: Human External Extensions]. M., Publ. Zhukovskij, KANON-press-C, Kuchkovo pole, 464 p. (McLuhan M. 1964. Understanding Media: The Extensions of Man. New York, McGraw-Hill, 318 p.)

12. Svetana S.V. 1976. Televizionnaja rech'. Funkcii i struktura [Television speech. Functions and structure]. Ed. Ja.N. Zasursky. M., Publ. Izd-vo Mosk. un-ta, 151 p.

13. Tynjanov Ju.N. 1977. Ob osnovah kino [About the basics of cinema]. In: Ju.N. Tynjanov Pojetika. Istorija Literatury. Kino [Poetics. History of Literature. Cinema]. Ed. V. Kaverin. M., Publ. Nauka: $326-348$.

14. Sharonchikova L.V. 2011. Radioveshhanie i televidenie Francii [Radio and Television of France]. M., Publ. Mosk. un-ta, 222 p.

15. Bourdon J. 2001. Genres télévisuels et emprunts culturels. L'américanisation invisible des télévisions européennes. Réseaux, 107 (3): 209-236.

16. Forsgren M., Sullet-Nylander F. 2010. Genre médiatique, activités linguistiques et degré d'interactivité. Le cas du talk-show. In: Communication, 27(2): 76-101. URL: https://journals.openedition.org/communication/3080\#tocto1n5 (accessed: 22 July 2020).

\section{ИНФОРМАЦИЯ ОБ АВТОРЕ}

Горобий Алексей Викторович, кандидат исторических наук, соискатель кафедры журналистики, рекламы и связей с общественностью Тверского государственного университета, г. Тверь, Россия

\section{INFORMATION ABOUT THE AUTHOR}

Aleksey V. Gorobiy, Candidate of Historical Sciences, Applicant for the Department of Journalism, Advertising and Public Relations, Tver State University, Tver, Russia 